\title{
Digestive Surgery in Patients Treated with Antiplatelet Agents: How Risky?
}

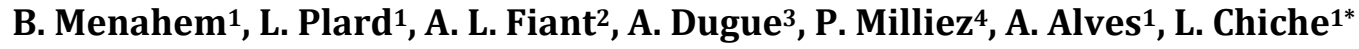 \\ ${ }^{1}$ Department of Digestive Surgery, University Hospital of Caen, Caen, France \\ ${ }^{2}$ Department of Anesthesiology, University Hospital of Caen, Caen, France \\ ${ }^{3}$ Department of Biostatistic, University Hospital of Caen, Caen, France \\ ${ }^{4}$ Department of Cardiology, University Hospital of Caen, Caen, France \\ Email: *laurence.chiche@chu-bordeaux.fr
}

Received 10 April 2014; revised 17 May 2014; accepted 26 May 2014

Copyright $(\subset) 2014$ by authors and OALib.

This work is licensed under the Creative Commons Attribution International License (CC BY). http://creativecommons.org/licenses/by/4.0/

(c) () Open Access

\begin{abstract}
Purpose: To assess the risks of digestive surgery in patients under antiplatelet therapy. Increasing numbers of patients requiring a surgical digestive procedure are on APT. Several studies have shown that APT interruption during the perioperative period increased thrombotic risks, while in the case of maintaining APT, hemorrhagic complications were not increased. Methods: We included prospectively all patients under APT who were operated on from September 1, 2010 to October 31, 2011. Two groups were defined: patients who interrupted APT and those who maintained APT. Three surgical categories were distinguished, with Group I involving parietal surgery, Group II common abdominal surgery, and Group III complex abdominal surgery. The primary endpoints were hemorrhagic and thrombotic risks. Results: Among the 2047 patients undergoing digestive surgery, 130 (6.5\%) were on APT, with 32 in Group APT- and 98 in Group APT+. In the overall series, patients taking APT did not receive significantly more transfusions. APT was significantly associated with a higher rate of bleeding complications and transfusion requirement in patients undergoing complex and major abdominal surgery ( $0 \%$ vs. $28 \%, p=0.03)$. In Group APT-, only one patient out of $32(3.1 \%)$ suffered from a thrombotic event involving a myocardial infarction. Conclusions: This study suggests stopping APT at least 5 - 7 days in patients undergoing complex and major abdominal surgery. In this other case, APT may be maintained without an increased risk of hemorrhage.
\end{abstract}

\section{Keywords}

Antiplatelet, Digestive Surgery, Hemorraghe, Thrombosis

\footnotetext{
*Corresponding author.
} 


\section{Introduction}

Increasing numbers of patients requiring elective surgery are on antiplatelet therapy (APT) either for vascular reasons (history of occlusive arterial disease of the lower limbs, transient ischemic attack, cerebrovascular accident) or for coronary disease with or without stents.

Several retrospective studies as well as a prospective randomized trial [1] have shown that the interruption of APT was associated with an increased risk of thrombosis. Moreover, APT maintenance was not associated with a significantly higher hemorrhagic risk. In addition, there are clear recommendations concerning patients with coronary stents and the management of APT in those patients likely to be operated on [2] [3].

Particularly in terms of hemorrhagic risks, no study to date has examined APT in the setting of digestive surgery alone. Furthermore, although the approach to APT in the case of stents is consensual, the perioperative management of diseases with different etiology appears to be less well codified.

Therefore, we conducted a prospective observational study in order to determine the risks of APT in patients requiring elective digestive surgery.

\section{Materials and Methods}

Among all patients operated on electively in the department of digestive surgery between September 1, 2010 and October 31, 2011, our study included prospectively only those receiving antiplatelet drugs (aspirin, clopidogrel, or aspirin-clopidogrel combination). Patients on treatment with anticoagulants exclusively or in combination with antiplatelet agents were excluded from the study. Two groups were subsequently defined: patients who interrupted APT (Group APT-) and those who maintained ATP (Group APT+).

All patients underwent a preoperative anesthesia consultation during which the following data pertaining to patient history, particularly cardiovascular history, was collected: type of stent and date of intervention, where applicable; American Society of Anesthesiologists (ASA) score; type of antiplatelet drugs; decision whether to interrupt APT or not; time required in the case of preoperative APT interruption. The intensive care anesthetist determined the approach to APT in line with the recommendations and in consultation with the surgeon. We considered APT to be interrupted preoperatively when the time between the interruption and surgery was at least 3 days.

Patient data relating to the type of surgical intervention and approach (laparotomy, laparoscopy) as well as to the pathology (cancerous, benign, or inflammatory) was collected. Patients were then classified into three surgical categories. Group I comprised patients undergoing parietal (hernia surgery and incisional hernia repair) and proctological surgery; Group II included patients undergoing common intra-abdominal surgery (cholecystectomy, biliary tract surgery, right or left colectomy, sleeve gastrectomy, surgery of static disorders, small bowel resection, and endocrine surgery); finally, Group III comprised patients undergoing major intra-abdominal surgery (esophagus and stomach surgery, liver and pancreatic surgery, proctectomy, subtotal colectomy, gastric bypass, and complex bile duct surgery).

Regarding per- and post-operative data, the major criteria studied were related to hemorrhagic and thrombotic risks, namely, the amount of blood loss during the intervention, need for a transfusion of labile blood products (red blood cells, fresh frozen plasma, or platelets), and preoperative (Day [D]-1) and postoperative (D1) platelet levels. For transfusions, the level of hemoglobin was set at $10 \mathrm{~g} / \mathrm{dL}$ in patients with high cardiovascular risk. As to postoperative data, we recorded postoperative blood loss, the aspect and duration of post-operative drainage, need for a transfusion of labile blood products, and finally, the development of thrombosis within 1 month following the intervention. Patients systematically underwent a postoperative consultation, involving an interview, clinical examination, and complementary investigations in the case of potential thrombotic complications.

Finally, the following secondary criteria were recorded: duration of operation, duration of hospitalization, and postoperative complications according to the Clavien-Dindo classification.

The times to APT resumption and to initiating anticoagulant therapy at a preventive dose were also recorded.

\section{Statistical Analysis}

Variables were expressed as mean \pm standard deviation, median [interquartile range], or number of patients (percentage) according to the type. Data at inclusion as well as per- and post-surgical data was compared between the two groups (APT interruption or maintenance) using Chi-squared or Fisher's exact test for qualitative 
variables, and Student's t or Manny-Whitney test for quantitative variables. Statistical analyses and figures were generated using the R software, version 2.13.1.

\section{Results}

In the period studied, 2047 patients were electively operated on in our department of digestive surgery. Among them, 130 patients were taking at least one APT. The main characteristics of the patient population are given in Table 1. The cohort comprised 46 women and 84 men, with a mean age of 67.5 years. The majority of patients $(n=125)$ were classified as ASA 2-3. As to the types of APT, 84 patients received aspirin preoperatively, 31 clopidogrel, 13 an aspirin-clopidogrel combination, and two prasugrel. For 30 patients, clopidogrel or prasugrel was replaced by aspirin. The main indications for APT were due to a cardiac etiology without stents in 56 patients (primary prevention, angina, persistent ductus arteriosus, heart transplant, and myocardial infarction without angioplasty and stent), the presence of stents in 32 patients, peripheral vascular disease in 22, and neurological causes in 10.

As to surgical interventions, 86 patients were operated on for a benign pathology and 44 for cancer. There were 35 patients in surgical Group I, 53 in Group II, and 42 in Group III. In terms of the maintenance or interruption of APT, Group APT+ comprised 98 patients who continued APT with 75mg aspirin, including those where clopidogrel or prasugrel was replaced by aspirin, while Group APT- comprised 32 patients who interrupted APT.

\subsection{Preoperative Data for Groups APT- and APT+}

The two groups were similar, particularly in terms of gender, age, ASA stage, pathology, surgical grade, and surgical approach ( $p=012,0.24,0.13,0.094,0.64,0.089$, and 0.059 , respectively), although there was a trend towards a higher rate of the laparotomy approaches in patients maintaining APT (Table 1).

Table 1. Patient characteristics for the series.

\begin{tabular}{|c|c|c|c|}
\hline & Group APT $-\quad n=32(\%)$ & Group APT $+n=98(\%)$ & $p$-value \\
\hline Gender & Female 15/Male 17 & Female 31/Male 67 & 0.12 \\
\hline Age & 65 [58.75 - 73.25] & 67.5 [62 - 76.75] & 0.24 \\
\hline \multicolumn{4}{|l|}{ ASA score } \\
\hline 1 & $1(3.1)$ & $0(0)$ & \multirow{4}{*}{0.13} \\
\hline 2 & $20(62.5)$ & 48 (49) & \\
\hline 3 & $11(34.4)$ & 46 (46.9) & \\
\hline 4 & $0(0)$ & $4(4.1)$ & \\
\hline \multicolumn{4}{|l|}{ APT } \\
\hline Aspirin & $17(53.1)$ & $67(68.4)$ & \multirow{4}{*}{0.094} \\
\hline Aspirin + clopidogrel & $2(6.3)$ & $11(11.2)$ & \\
\hline Clopidogrel & $13(40.6)$ & $18(18.4)$ & \\
\hline Prasugrel & $0(0)$ & $2(2)$ & \\
\hline \multicolumn{4}{|l|}{ Pathology } \\
\hline Benign & 23 (71.9) & $62(63.3)$ & \multirow{3}{*}{0.64} \\
\hline Cancer & $9(28.1)$ & $35(35.7)$ & \\
\hline Inflammatory & $0(0)$ & $1(1)$ & \\
\hline \multicolumn{4}{|l|}{ Surgical grade } \\
\hline I & $5(15.6)$ & $30(30.6)$ & \multirow{3}{*}{0.089} \\
\hline II & $12(37.5)$ & 41 (41.8) & \\
\hline III & 15 (46.9) & $27(27.6)$ & \\
\hline \multicolumn{4}{|l|}{ Surgical procedure } \\
\hline Cervicotomy & $0(0)$ & $3(3)$ & \multirow{4}{*}{0.059} \\
\hline Coelioscopy & $12(37.5)$ & $27(27.6)$ & \\
\hline Laparotomy & $18(56.3)$ & $68(69.4)$ & \\
\hline Proctology & $2(6.2)$ & $0(0)$ & \\
\hline
\end{tabular}

APT: antiplatelet therapy; ASA: American Society of Anesthesiologists. 


\subsection{Per- and Postoperative Data}

\subsubsection{Main Criteria: Hemorrhage and Thrombosis}

Data from the per-operative period is provided in Table 2. In the overall series, patients operated on while continuing APT did not require significantly more transfusions and they did not suffer more blood loss. A summary of the hemorrhagic complications is given in Table 3. Nevertheless, the only patients receiving transfusions in the peroperative period were under APT. Particularly in terms of Group III patients who underwent major surgery, the patients under APT experienced more hemorrhagic complications and received significantly more transfusions $(p=0.03)$ (Table 4). Moreover, in the entire patient cohort, postoperative platelet levels were significantly higher in patients operated on under APT $(p=0.048)$.

Postoperative data for the two groups is summarized in Table 5. Patients who maintained APT did not undergo significantly more drainage procedures than those who interrupted APT $(p=0.54)$. The aspect of the drainage fluid was identical in the both groups at the three sampling dates, $(p=1.0,0.87$, and 0.22 for D1, D3, and D7, respectively) (Table 5). Examining the duration of drainages, the curves were found to be superimposable in the two groups $(p=0.5)$ (Figure 1$)$.

In the group interrupting APT, only one patient experienced a thrombotic episode, notably myocardial infarction. The duration of hospitalization was identical in both groups $(p=0.43)$.

\subsubsection{Other Study Criteria}

The duration of surgery was comparable in the two groups ( $p=0.38)$.

There were not significantly more Clavien Grade > IIIa complications in Group APT+ compared with Group APT $-(p=0.72)$. A total of 23 events were recorded, with 18 in patients maintaining APT (Group APT + ) versus five in those interrupting APT (Group APT-). In addition, the rates for revision surgery and intensive care stays were not significantly higher in either of the two groups.

Nonetheless, in our patient cohort, three deaths were reported, all of which affected patients from Group APT+. One patient presented major cardiac failure, another acute respiratory distress with aspiration pneumonia, while the third presented symptomatic evisceration on postoperative peritonitis secondary to a fistula due to perianastomotic hematoma. The main characteristics of the deceased patients are given in Table 6 .

Table 2. Per-operative data.

\begin{tabular}{|c|c|c|c|}
\hline & Group APT $-\quad n=32(\%)$ & Group APT $+n=98(\%)$ & $p$-value \\
\hline Duration of intervention (min) & $120[60-150]$ & $85[60-147.5]$ & 0.38 \\
\hline $\begin{array}{l}\text { Transfusion } \\
\text { No } \\
\text { Yes }\end{array}$ & $\begin{array}{c}32(100) \\
0(0)\end{array}$ & $\begin{array}{c}93(94.9) \\
5(5.1)\end{array}$ & 0.33 \\
\hline $\begin{array}{l}\text { Volume of blood loss (mL) } \\
\text { Mean } \\
\text { Median ( } 5-95^{\text {eme }} \text { percentile) } \\
\text { Maximum }\end{array}$ & $\begin{array}{c}169 \\
0[0-350] \\
1300\end{array}$ & $\begin{array}{c}129 \\
0[0-150] \\
1300\end{array}$ & 0.93 \\
\hline Number of red blood cell packs transfused & 0 & 10 in 5 patients & 0.19 \\
\hline Preoperative platelet count & $187,000[167,000-203,000]$ & $200,000[178,000-221,500]$ & 0.096 \\
\hline Postoperative platelet count & $197,000[180,000-215,000]$ & $212,000[187,500-231,500]$ & 0.048 \\
\hline
\end{tabular}

Table 3. Hemorrhagic complications.

\begin{tabular}{ccc}
\hline & Group APT- APT + & Galue \\
\hline Type of complications & & 3 \\
Parietal wall hematoma & 1 & 3 \\
Perinastomotic hematoma & 0 & 0 \\
Collection hepatectomy slice & 1 & 1 \\
Hemobilia & 0 & 0.50 \\
\hline
\end{tabular}


Table 4. Pre- and postoperative data for Group III patients.

\begin{tabular}{|c|c|c|c|}
\hline & Group APT- (17) & Group APT+ (25) & p-value \\
\hline \multicolumn{4}{|l|}{ Age } \\
\hline \multicolumn{4}{|l|}{ ASA score } \\
\hline 1 & 1 & 0 & \multirow{4}{*}{0.22} \\
\hline 2 & 8 & 12 & \\
\hline 3 & 8 & 9 & \\
\hline 4 & 0 & 4 & \\
\hline \multicolumn{4}{|l|}{ APT } \\
\hline Aspirin & 12 & 10 & \multirow{4}{*}{0.31} \\
\hline Aspirin + clopidogrel & 4 & 9 & \\
\hline Clopidogrel & 1 & 4 & \\
\hline Prasugrel & 0 & 2 & \\
\hline \multicolumn{4}{|l|}{ Reason for APT } \\
\hline Stent & 0 & 10 & \multirow{4}{*}{0.0070} \\
\hline Cardiac without stent & 13 & 11 & \\
\hline Neurological & 2 & 2 & \\
\hline Vascular & 2 & 2 & \\
\hline \multicolumn{4}{|l|}{ Perioperative transfusion } \\
\hline Yes & 0 & 5 & \multirow{2}{*}{0.070} \\
\hline No & 17 & 20 & \\
\hline \multicolumn{4}{|c|}{ Perioperative red blood cell packs } \\
\hline Yes & 0 & 10 & \multirow{2}{*}{0.0026} \\
\hline No & 17 & 15 & \\
\hline \multicolumn{4}{|l|}{ Postoperative transfusion } \\
\hline Yes & 0 & 7 & \multirow{2}{*}{0.030} \\
\hline No & 17 & 18 & \\
\hline \multicolumn{4}{|c|}{ Postoperative red blood cell packs } \\
\hline Yes & 0 & 11 & \multirow{2}{*}{0.0012} \\
\hline No & 17 & 14 & \\
\hline \multicolumn{4}{|l|}{ Drainage } \\
\hline Yes & 17 & 23 & \multirow[t]{2}{*}{0.51} \\
\hline No & 0 & 2 & \\
\hline \multicolumn{4}{|l|}{ Clavien classification } \\
\hline I & 7 & 12 & \multirow{7}{*}{0.94} \\
\hline II & 5 & 5 & \\
\hline IIIa & 2 & 4 & \\
\hline IIIb & 1 & 2 & \\
\hline Iva & 2 & 2 & \\
\hline $\mathrm{IVb}$ & 0 & 0 & \\
\hline $\mathrm{V}$ & 0 & 0 & \\
\hline
\end{tabular}

APT: antiplatelet therapy; ASA: American Society of Anesthesiologists.

When the characteristics of patients presenting a postoperative event (Clavien IIIa) were compared with those who did not, the presence of cancer was found to be a significant factor $(p<0.00011)$, whereas APT was not (Table 7).

When considering the rate of events in terms of the three predefined surgical groups, we observed that surgical category did not play a statistically significant role (Figure 2), and nor did ASA classification. It should be noted; however, that complications were observed in all ASA Grade 4 patients (Figure 3).

\section{Discussion}

Over the last few years, there has been a significant improvement in the management of cardiovascular diseases, 
Table 5. Postoperative data.

\begin{tabular}{|c|c|c|c|}
\hline & Group $1 \quad n=32(\%)$ & Group $2 n=98(\%)$ & $P$-value \\
\hline \multicolumn{4}{|l|}{ Drainage } \\
\hline No & $14(43.75)$ & $49(50)$ & 0.54 \\
\hline Yes & $18(56.25)$ & $49(50)$ & \\
\hline \multicolumn{4}{|l|}{ Appearance of drainage } \\
\hline Day 1: Hematic & 16(88.9) & 41 (91.1) & \\
\hline Serous & $2(11.1)$ & $4(8.9)$ & 1 \\
\hline Day 3: Hematic & $9(50)$ & $23(52.3)$ & \\
\hline Serous & $9(50)$ & $21(47.7)$ & 0.87 \\
\hline Day 7: Hematic & $0(0)$ & $4(25)$ & \\
\hline Foul & $1(14.3)$ & $0(0)$ & 0.22 \\
\hline Serous & $6(85.7)$ & $12(75)$ & \\
\hline Duration of drainage(days) & $6[5-7.75]$ & $6[5-7]$ & 0.33 \\
\hline \multicolumn{4}{|l|}{ Intensive care stay } \\
\hline No & 30 (93.75) & $91(93.5)$ & 1 \\
\hline Yes & $2(6.25)$ & $7(6.5)$ & \\
\hline $\begin{array}{c}\text { Duration of intensive care stay } \\
\text { (days) }\end{array}$ & $21[14-28]$ & $10[7.75-12.25]$ & 0.74 \\
\hline \multicolumn{4}{|l|}{ Volume of blood loss (mL) } \\
\hline Mean & 9.3 & 31.6 & \\
\hline Median (5-95 ${ }^{\text {eme }}$ percentile) & $0[0-0]$ & $0[0-0]$ & 0.68 \\
\hline Maximum & 200 & 900 & \\
\hline \multicolumn{4}{|c|}{ Number of red blood cell packs transfused } \\
\hline Mean & 0.05 & 0.16 & \\
\hline Median (5 - 95 $5^{\text {ème }}$ percentile) & 1 & 8 & 0.42 \\
\hline Maximum & 2 & 15 & \\
\hline \multicolumn{4}{|l|}{ Clavien classification } \\
\hline I & $20(62.5)$ & $69(70.4)$ & \\
\hline II & 7 (21.9) & $11(11.2)$ & \\
\hline IIIa & $2(6.3)$ & $10(10.2)$ & 0.47 \\
\hline IIIb & $1(3.1)$ & $2(2)$ & \\
\hline IVa & $2(6.3)$ & $3(3.1)$ & \\
\hline V & $0(0)$ & $3(3.1)$ & \\
\hline \multicolumn{4}{|l|}{ Number of events (>IIIa) } \\
\hline No & $27(84.4)$ & $80(81.7)$ & 0.72 \\
\hline Yes & $5(15.6)$ & $18(18.3)$ & \\
\hline Duration of hospitalization & $7[4-11]$ & $6[4-10]$ & 0.43 \\
\hline \multicolumn{4}{|l|}{ Revision surgery } \\
\hline No & $32(100)$ & $93(94.9)$ & \\
\hline Yes & $0(0)$ & $5(5.1)$ & \\
\hline \multicolumn{4}{|l|}{ Postoperative thrombosis } \\
\hline No & 31 (96.9) & $94(100)$ & \\
\hline Yes & $1(3.1)$ & $0(0)$ & \\
\hline
\end{tabular}

especially coronary disease with the rise of interventional treatments (coronary stents and associated APT). Today, it is no longer rare to operate on a patient with a more or less severe cardiac history in whom APT was initiated.

In our series, $6.5 \%$ of the operated population was under APT, which is in line with the 5\% rate reported in the literature [4].

Hemorrhagic risk is a major preoccupation of the digestive surgeon, particularly in difficult surgical procedures (i.e., hepatectomy, pancreatectomy, esophagectomy, or proctectomy). The use of antiplatelet agents reinforces this concern, often leading to the interruption of APT. However, this interruption exposes the patient to an 


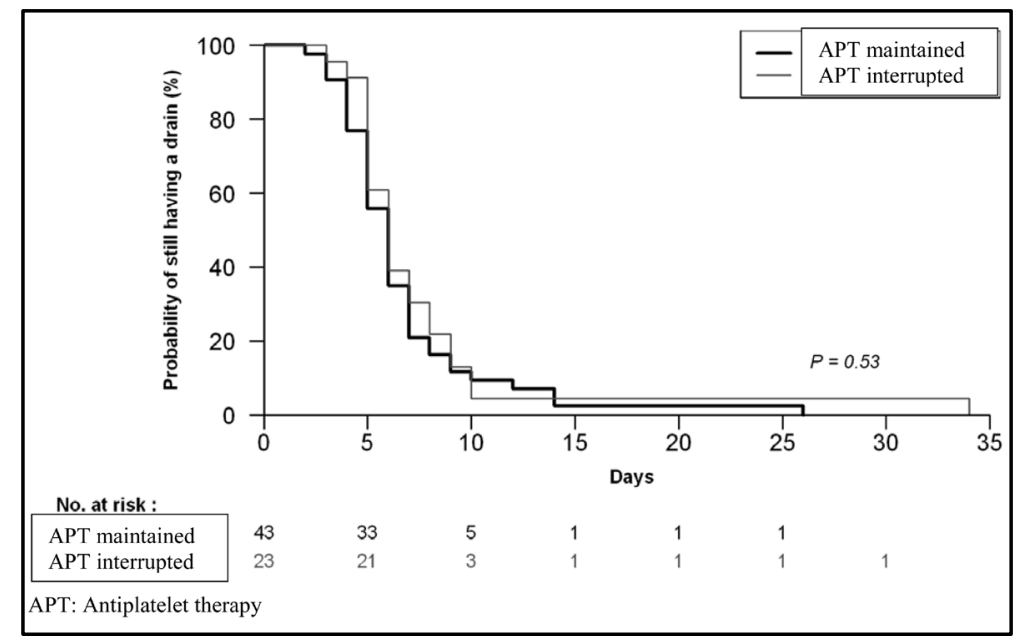

Figure 1. Duration of surgical drainage in the two groups.

Table 6. Postoperative data.

\begin{tabular}{|c|c|c|c|c|c|c|c|c|c|}
\hline Patient & Age & $\begin{array}{l}\text { ASA } \\
\text { score }\end{array}$ & Stent & Pathology & $\begin{array}{l}\text { Intervention type } \\
\text { (surgical category) }\end{array}$ & $\begin{array}{l}\text { Perioperative } \\
\text { transfusion }\end{array}$ & Drainage & Cause of death & $\begin{array}{c}\text { Revision } \\
\text { surgery }\end{array}$ \\
\hline No 1 & 46 & 4 & no & Cancer & Surrenalectomy (II) & No & Yes & Cardiac failure & No \\
\hline No 2 & 79 & 3 & no & Cancer & Left colectomy (II) & No & Yes & $\begin{array}{l}\text { Acute respiratory distress } \\
\text { with aspiration pneumonia }\end{array}$ & No \\
\hline No 3 & 74 & 3 & yes & Benign & Left colectomy (II) & No & Yes & $\begin{array}{c}\text { Postoperative fistula } \\
\text { secondary to perianastomotic } \\
\text { hematoma (septic shock) }\end{array}$ & Yes \\
\hline
\end{tabular}

Table 7. Factors favoring the occurrence of postoperative events (Clavien $\geq$ IIIa).

\begin{tabular}{|c|c|c|c|}
\hline & Clavien < IIIa $n=101$ (\%) & Clavien $\geq$ IIIa $\quad n=23(\%)$ & $P$ value \\
\hline Age (years) & 67.9 & 65.2 & 0.30 \\
\hline \multicolumn{4}{|l|}{ Antiplatelet type } \\
\hline Aspirin & $68(63.6)$ & $16(69.6)$ & \multirow{4}{*}{0.43} \\
\hline Aspirin + clopidogrel & $12(11.2)$ & $1(4.3)$ & \\
\hline Clopidogrel & $1(0.9)$ & $1(4.3)$ & \\
\hline Prasugrel & $26(24.3)$ & $5(21.8)$ & \\
\hline \multicolumn{4}{|l|}{ Pathology } \\
\hline Cancer & $29(27.1)$ & $15(65.2)$ & \multirow{3}{*}{0.00011} \\
\hline Benign & $78(72.9)$ & $7(30.4)$ & \\
\hline Inflammatory & $0(0)$ & $1(4.4)$ & \\
\hline \multicolumn{4}{|l|}{ History } \\
\hline Cardiac & 55 (51.4) & $12(52.2)$ & \multirow{4}{*}{0.58} \\
\hline Neurological & $10(9.4)$ & $1(4.4)$ & \\
\hline Stent & $23(21.5)$ & $7(30.4)$ & \\
\hline Vascular & $20(18.7)$ & $3(13)$ & \\
\hline
\end{tabular}

equally dangerous thrombotic risk, which is further increased in the postoperative setting by a more or less marked inflammatory reaction. This theoretical data is supported by the literature [5]-[10]. The study of Collet $e t$ al. [11] revealed the risk of acute coronary syndrome from interrupting APT prior to surgery. Other cohort studies observed various thrombotic events (stroke, acute ischemia of the limbs, etc.) that were associated with stopping APT [12]-[16]. A randomized trial investigated the impact of the perioperative management of APT, 


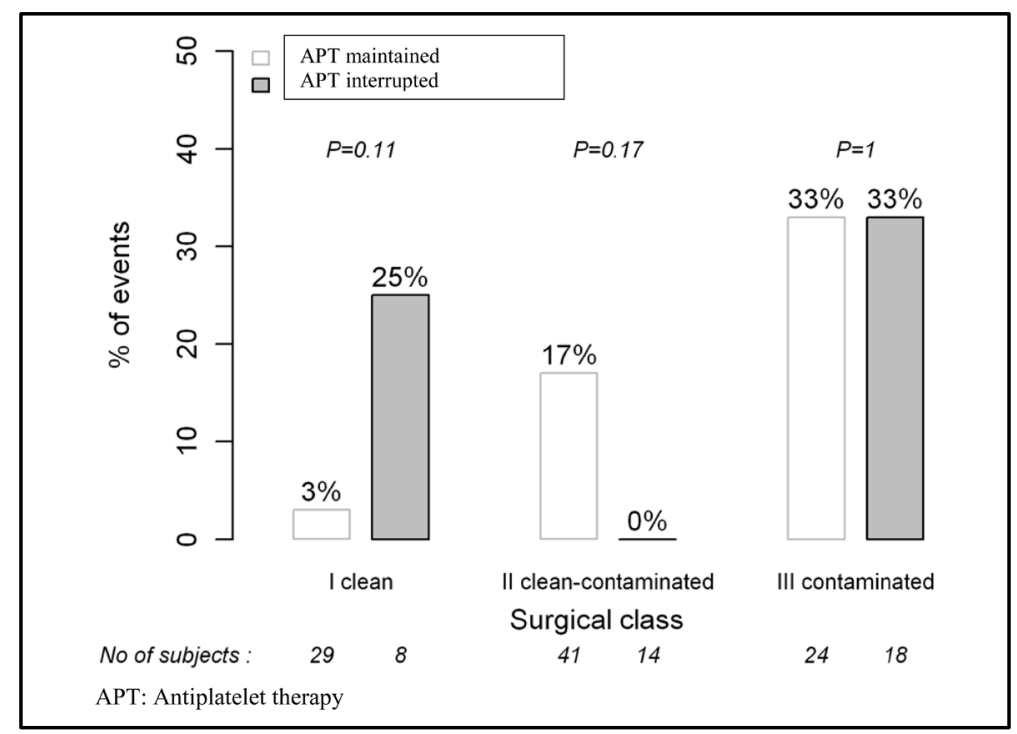

Figure 2. Number of events in relation to surgical grade.

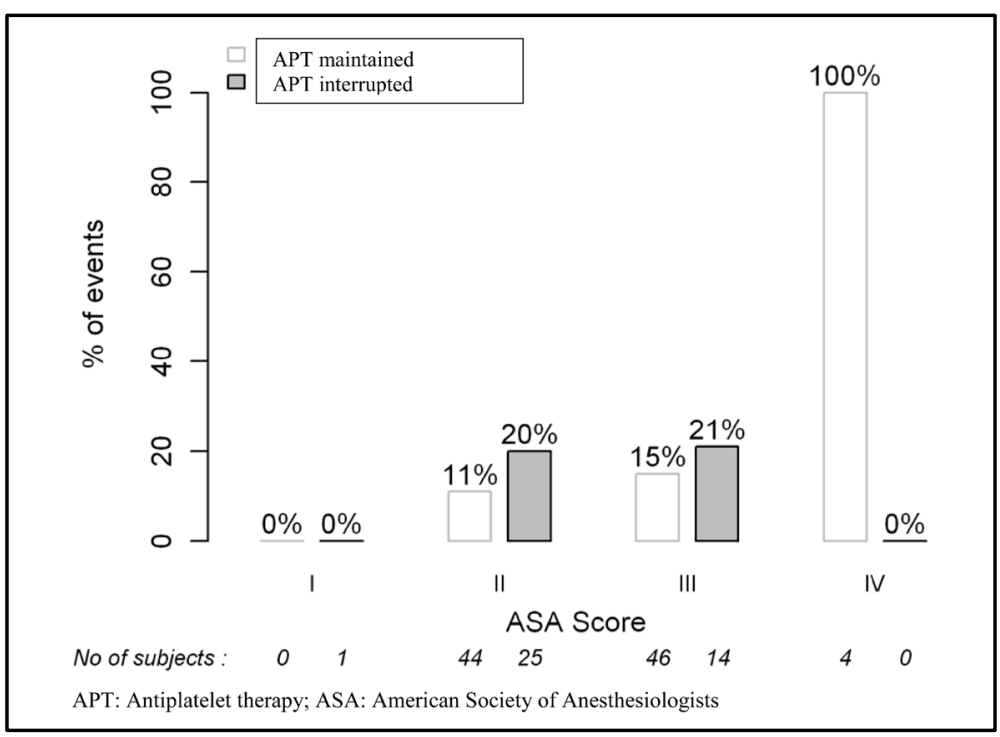

Figure 3. Number of events in relation to American Society of Anesthesiologists’ score.

showing a reduction in thrombotic cardiovascular events in the group receiving aspiring. In contrast, no significant differences were found for perioperative hemorrhagic events [17]. In terms of patients with stents, a study published in 2000 reported on a cohort of patients undergoing emergency surgery in the weeks following the positioning of a bare-metal stent. In these patients, the postoperative mortality rate was close to $20 \%$ due to hemorrhagic or thrombotic events [18].

To date, few studies have evaluated the surgical risk of hemorrhage associated with the perioperative use of APT, particularly in the setting of digestive surgery. Burger et al. conducted a meta-analysis of 41 studies comprising 49,950 patients, with 14,981 taking aspirin. The frequency of hemorrhagic complications was found to vary from $0 \%$ (cataract) to $75 \%$ (prostate biopsy) depending on the procedure performed [19].

Our series, which was the first to study digestive surgery specifically, confirmed the absence of increased risk in terms of per- or postoperative hemorrhages for patients undergoing surgery while being treated with antiplatelet agents. Although, patients on anti-platelet therapy undergoing complex and major abdominal surgery (Group III) have a significantly higher rate of bleeding complications and transfusion requirement, a multifac- 
torial analysis of the entire series revealed that the use of antiplatelet agents was not significantly associated with an increase in morbi-mortality. Only cancer played a significant role.

In our series, the decision was taken to interrupt APT in $25 \%$ of all patients prior to surgery at the cost of one successfully treated thrombosis case, whereas in the group where APT was maintained, no thrombotic events were recorded. The absence of increased morbidity in association with the continuation of antiplatelet agents supports the recommendation of not stopping APT whatever the pathology.

Finally, in a certain number of patients, clopidogrel or prasugrel treatment was replaced by aspirin, which was not related to any adverse event, which would further validate such an approach.

The mortality rate was three out of 130 patients (2.3\%), which was rather low given that 42 of these patients (32.3\%) underwent major surgery and that the overall patient population exhibited considerable cardiovascular risk factors (61 patients or $46.9 \%$ with an ASA score > 2).

Limitations of the current study include not only the limited number of patients but also the absence of a true control group. Although the power is limited, there is no significant difference between two groups, according to age, sex, operation, and study period. To our knowledge, the only randomized study, conducted for all types of surgery, had to be prematurely stopped due to the insufficient patient inclusions (1).

To conclude, the use of APT was not associated with increased morbi-mortality in the setting of elective digestive surgery, which ranged from simple to more complex procedures. Maintaining APT in coronary patients prevented thrombotic risks without increasing risk of hemorrhage, expect perhaps in the case of major interventions, which resulted in higher transfusion rates without corresponding increases in morbi-mortality rates. We suggest stopping anti-platelet therapy at least 5 - 7 days in this cohort of patients undergoing major or complex surgery.

It is therefore possible, even desirable, to maintain APT in patients requiring this treatment for any reason and for any procedure in digestive surgery.

\section{Conflict of Interest Statement}

Menahem B and other co-authors have no conflict of interest.

\section{References}

[1] Mantz, J., Samama, C.M., Tubach, F., Devereaux, P.J., Collet, J.P., Albaladejo, P., Cholley, B., Nizard, R., Barré, J., Piriou, V., Poirier, N., Schlumberger, S., Longrois, D., Aubrun, F., Farèse, M.E., Ravaud, P. and Steg, P.G. (2011) Impact of Preoperative Minteanance or Interruption of Aspirin on Thrombotic and Bleeding Events after Elective Non-Cardiac Surgery: The Multicentre, Randomized, Blinded, Placebo-Controlled, Strategem Trial. British Journal of Anaesthesia, 107, 899-910. http://dx.doi.org/10.1093/bja/aer274

[2] Samama, C.M., Bartim, O., Forestier, F., Denninger, M.H., Isettra, C., Julian, J.M., et al. (2002) Antiplatelets Agents in the Perioperative Period: Expert Recommendations of the French Society of Anesthesiology and Intensive Care. Canadian Journal of Anesthesia, 49, S26-35.

[3] Riddell, J.W., Chiche, L., Plaud, B. and Hamon, M. (2007) Coronary Stenting and Noncardiac Surgery. Circulation, 116, e378-382. http://dx.doi.org/10.1161/CIRCULATIONAHA.107.726992

[4] Korte, W., Cattaneo, M., Chassot, P.G., Eichinger, S., von Heymann, C., Hofmann, N., Rickli, H., Spannagl, M., Ziegler, B., Verheugt, F. and Huber, K. (2011) Peri-Operative Management of Antiplatelet Therapy in Patients with Coronary Artery Disease: Joint Position Paper by Members of the Working Group on Perioperative Haemostasis of the Society on Thrombosis and Haemostasis Research (GTH), the Working Group on Perioperative Coagulation of the Austrian Society for Anesthesiology, Resuscitation and Intensive Care (ÖGARI) and the Working Group Thrombosis of the European Society for Cardiology (ESc). Thrombosis and Haemostasis, 105, 743-749. http://dx.doi.org/10.1160/TH10-04-0217

[5] Albaledjo, P. and Samama, C.-M. (2010) Gestion périopératoire des anciens et nouveaux agents antiplaquettaires. Le Praticien en Anesthésie-Réanimation, 14, 44-50.

[6] Chassot, P.G., Delabays, A. and Spahn, D.R. (2007) Perioperative Antiplatelet Therapy: The Case for Continuing Therapy in Patients at Risk of Myocardial Infarction. British Journal of Anaesthesia, 99, 316-328. http://dx.doi.org/10.1093/bja/aem209

[7] Nuttal, G.A., Brown, M.J., Stombaugh, J.W., Michon, P.B., Hathaway, M.F., Lindeen, K.C., et al. (2008) Time and Cardiac Risk of Surgery after Bare-Metal Stent Percutaneous Coronary Intervention. Anesthesiology, 109, 588-595. http://dx.doi.org/10.1097/ALN.0b013e318186ddf8 
[8] Rabbits, J.A., Nuttal, G.A., Brown, M.J., Hanson, A.C., Oliver, W.C., Holmes, D.R., et al. (2008) Cardiac Risk of Non Cardiac Surgery after Percutaneous Coronary Intervention with Drug-Eluting Stents. Anesthesiology, 109, 596-604. http://dx.doi.org/10.1097/ALN.0b013e318186de1c

[9] Douketis, J.D., Berger, P.B., Dunn, A.S., Jaffer, A.K., Spyropoulos, A.C., Becker, R.C., et al. (2008) The Perioperative Management of Antithrombotic Therapy: American College of Chest Physicians Evidence-Based Clinical Practice Guidelines (8th Edition). Chest, 133, S299-349.

[10] Iakovou, I., Schmidt, T., Bonizzoni, E., Ge, L., Sangiorgi, G.M., Stankovic, G., et al. (2005) Incidence, Predictors, and Outcome of Thrombosis after Succesful Implantation of Drug-Eluting Stents. JAMA, 293, 2126-2130. http://dx.doi.org/10.1001/jama.293.17.2126

[11] Collet, J.P., Montalescot, B., Tanguy, M.L., Goldmard, J.L., Choussat, R., Beygui, F., Payot, L., Vignolles, N., Metzger, J.P. and Thomas, D. (2004) Impact of Priori Use or Recent Withdrawal of Oral Antiplatelet Agents on Acute Coronary Syndromes. Circulation, 110, 2361-2367. http://dx.doi.org/10.1161/01.CIR.0000145171.89690.B4

[12] Albaledjo, P., Geeraerts, T., Francis, F., Castier, Y., Leseche, G. and Marty, J. (2004) Aspirin Withdrawal and Acute Lower Limb Ischemia. Anesthesia \& Analgesia, 99, 440-443. http://dx.doi.org/10.1213/01.ANE.0000131965.61686.BD

[13] Bachman, D.S. (2002) Discontinuing Chronic Aspirin Therapy: Another Risk Factor of Stroke? Annals of Neurology, 51, 137-138. http://dx.doi.org/10.1002/ana.10023

[14] Ferrari, E., Benhamou, M., Cerboni, P. and Marcel, B. (2005) Coronary Syndromes Following Aspirin Withdrawal a Special Risk for Late Stent Thrombosis. Journal of the American College of Cardiology, 45, 456-459. http://dx.doi.org/10.1016/j.jacc.2004.11.041

[15] Maulaz, A.B., Bezerra, D.C., Michel, P. and Bogoulavsky, J. (2005) Effects of Discontinuing Aspirin Therapy on the Risk of Brain Ischemic Stroke. Archives of Neurology, 62, 1217-1220. http://dx.doi.org/10.1001/archneur.62.8.1217

[16] Sibon, I. and Orgogozo, J.M. (2004) Antiplatelet Drug Discontinuation Is a Risk Factor for Ischemic Stroke. Neurology, 62, 1187-1189. http://dx.doi.org/10.1212/01.WNL.0000118288.04483.02

[17] Oscarsson, A., Gupta, A., Fredrikson, M., Jarhult, J., Nystrom, M., Pettersson, E., et al. (2010) To Continue or Discontinue Aspirin in the Perioperative Period: A Randomized, Controlled Clinical Trial. British Journal of Anaesthesia, 104, 305-312. http://dx.doi.org/10.1093/bja/aeq003

[18] Kaluza, G.L., Joseph, J., Lee, J.R., Raizner, M.E. and Raizner, A.E. (2000) Catastrophic Outcomes of Non Cardiac Surgery Soon after Coronary Stenting. Journal of the American College of Cardiology, 35, 1288-1294. http://dx.doi.org/10.1016/S0735-1097(00)00521-0

[19] Burger, W., Chmnitius, J.M., Kneiss, G.D. and Rucker, G. (2005) Low-Dose of Aspirin for Secondary Cardiovascular Prevention-Cardiovascular Risks after Its Perioperative Withdraal versus Bleeding Risks with Its Continuation-Review and Metanalysis. Journal of Internal Medicine, 257, 399-414. http://dx.doi.org/10.1111/j.1365-2796.2005.01477.x 